\title{
Carmen Lyra y el Centenario de Los cuentos de mi tía Panchita
}

\author{
Lacayo Campos, Mariana \\ Carmen Lyra y el Centenario de Los cuentos de mi tía Panchita \\ Revista Educación, vol. 44, núm. 2, 2020 \\ Universidad de Costa Rica, Costa Rica \\ Disponible en: http://www.redalyc.org/articulo.oa?id=44062184035 \\ DOI: https://doi.org/10.15517/revedu.v44i2.42556
}

Esta obra está bajo una Licencia Creative Commons Atribución-NoComercial-SinDerivar 3.0 Internacional. 


\section{Carmen Lyra y el Centenario de Los cuentos de mi tía Panchita}

Mariana Lacayo Campos

Universidad de Costa Rica, Costa Rica

mariana.lacayo@ucr.ac.cr

(iD http://orcid.org/0000-0001-5900-4020
DOI: https://doi.org/10.15517/revedu.v44i2.42556

Redalyc: http://www.redalyc.org/articulo.oa?id=44062184035

En abril de 1920 se publicó por primera vez el libro Los cuentos de mi tía Panchita, de la autora costarricense Carmen Lyra; este 2020 se conmemora su centenario y la Revista Educación de la Universidad de Costa Rica, le dedica este editorial.

\section{Biografía}

María Isabel Carvajal Castro (apellidos maternos que ella adoptó), mejor conocida como Carmen Lyra, su seudónimo, nació en San José, el 15 de enero de 1887, según un estudio genealógico elaborado por LemistrePujol (2015), quien tuvo acceso a su fe de bautismo, sin embargo, en su pasaporte emitido en Francia, se registró 1888 como año de nacimiento.

Cursó sus estudios de secundaria en el Colegio Superior de Señoritas, de donde se graduó como maestra normal en 1904. En 1906 ejecutó labores de acción social como novicia, de la Orden de las Hermanas de la Caridad en el Hospital San Juan de Dios. 


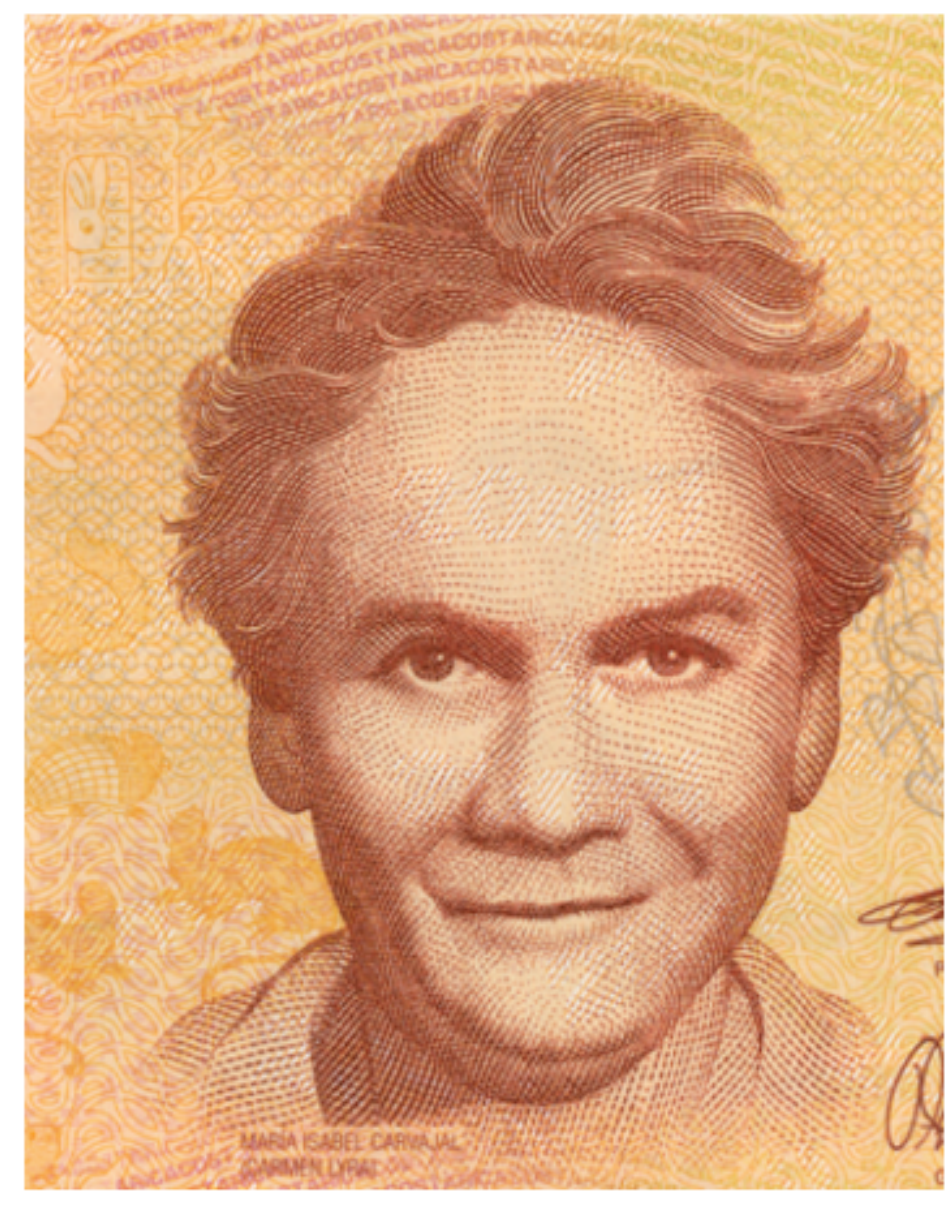

\section{FIGURA 1}

Homenaje a Carmen Lyra en el billete de 20.000 colones Fuente: Banco Central de Costa Rica (s.f.).

\section{APORTES EN PUBLICACIONES PERIÓDICAS}

Carmen Lyra publicó sus obras en revistas como Páginas Ilustradas desde diciembre de 1905, Selenia en 1910, Cordelia en 1913, Pandemónium en 1914, Colección Ariel en 1916, Athenea en 1917, Repertorio Americano en 1920 (firmando como Marisabel C.), Ardua en 1922, El Maestro en 1926 y Brecha en 1958, entre otras. Además, sus escritos se divulgaron en el periódico Trabajo del Partido Comunista de Costa Rica, desde su primer número.

Fundó, en coedición con Lilia González, San Selerín: periódico para niños, fue una de las primeras revistas infantiles de Costa Rica, publicada de forma quincenal en dos etapas, de 1912 a 1913 y de 1923 a 1924, en ella divulgó los primeros escritos que luego formarían parte de Cuentos de mi tía Panchita, entre ellos: Aventuras de tio Conejo: el viejo de la montaña, Las Aventuras de Tio Conejo, El Caballo de Tio Conejo, entre otros.

Fue directora de la revista Renovación: literatura, ciencias y critica bibliográfica en 1914 hasta su cierre por falta de recursos económicos, en ella se promovió la literatura nacional costarricense y publicó seis escritos de su autoría. 


\section{LIBROS}

Escribió su primera obra, En una silla de ruedas, antes de cumplir los 20 años, esta se publicó en 1917, posteriormente, Las fantasías de Juan Silvestre, en 1918. En el año 1920 publicó Cuentos de mi tía Panchita, el cual instauró los inicios de la literatura infantil costarricense.

\section{Política}

Dirigió la manifestación contra la dictadura de los hermanos Tinoco, el 13 de junio de 1919, en la cual participaron maestras y culminó con la quema de la imprenta donde se editaba el periódico La Información, posteriormente cayó la dictadura.

A partir de 1931 se unió al Partido Comunista, como una de las personas fundadoras, publicó en el periódico Trabajo, editado por este partido político, en el cual denunciaba actos de injusticia y corrupción. En 1934 se involucró en la huelga bananera de Costa Rica, ya en 1931, entre mayo y junio, había publicado en Repertorio Americano, cuatro relatos cortos de la serie titulada Bananos y hombres, describiendo la realidad vivida por las personas cercanas a las bananeras.

\section{MAESTRA}

En 1920, bajo el mandato del presidente Julio Acosta García, fue becada para educarse en Europa, principalmente en Francia, para perfeccionar los estudios relacionados con enseñanza primaria. Es allí donde conoce el método Montessori y los aportes de Decroly. En 1921 inició como maestra de la cátedra de Literatura infantil y otros cursos relacionados con la higiene, en la Escuela Normal de Costa Rica. En 1925 fundó la Escuela Maternal en San José, para la educación preescolar, allí continuó con las prácticas y cursos de higiene y además implementó el "servicio de la leche", el cual consistía en dar alimentos a niños y niñas, a partir de esa iniciativa surgieron los comedores escolares. En 1933, al formar parte del Partido Comunista, fue separada de su puesto como directora de la Escuela Maternal. En 1936 comenzó sus labores en el Patronato Nacional de la Infancia (PANI).

En 1937 se desempeñó como directora de la Escuela Popular, instaurada por el Partido Comunista. A inicios de la década de 1940, estableció en su casa la Universidad Popular, espacio dedicado a la enseñanza en donde se impartía lecciones y conferencias, además, se prestaban y vendían libros.

\section{EXILIO Y MUERTE}

Carmen Lyra fue exiliada de su país, en un principio se refugió en la Embajada de México en Costa Rica, posteriormente fue expulsada y enviada a México el 23 de abril de 1948, al finalizar la Guerra Civil del 48. En varias ocasiones solicitó la repatriación, sin embargo, esta fue denegada por la Junta de Gobernación.

Carmen Lyra falleció el 14 de mayo de 1949 en Ciudad de México, sus restos fueron velados en la Confederación de Trabajadores de América Latina (en México), llegaron a Costa Rica el 20 de mayo, y fueron sepultados el 22 de mayo en el Cementerio General de San José.

\section{HoMENAJES}

En 1962, la Junta de Educación del Distrito de Cóbano de Puntarenas acordó denominar la Escuela Carmen Lyra; años más tarde, la escuela de Concepción de Alajuelita adoptó también su nombre. 
En 1971, se fundó la Biblioteca Infantil Carmen Lyra, en la planta baja del quiosco del Parque Central de San José, fue cerrada en 1993.

El 28 de julio de 1976, la Asamblea Legislativa de la República de Costa Rica, declaró Benemérita de la Cultura Nacional a María Isabel Carvajal Quesada (Carmen Lyra), mediante Decreto $\mathrm{N}^{\circ} 1679$. (Asamblea Legislativa., 6 de agosto de 1976).

Desde 2010, como homenaje a Carmen Lyra, se utiliza su imagen para ilustrar el billete de 20.000 colones, emitido por el Banco Central de Costa Rica (BCCR) (ver Figura 1). También presenta en su motivo principal, otra ilustración, alusiva a Los Cuentos de mi tía Panchita (ver Figura 2).

En el 2006 la Municipalidad de San José creó la Biblioteca Carmen Lyra en Pavas.

El 26 de abril de 2016, fue declarada Benemérita de la Patria, por acuerdo Nº612-15-16 del 16 de abril del 2016. (Asamblea Legislativa, 16 de mayo de 2016).

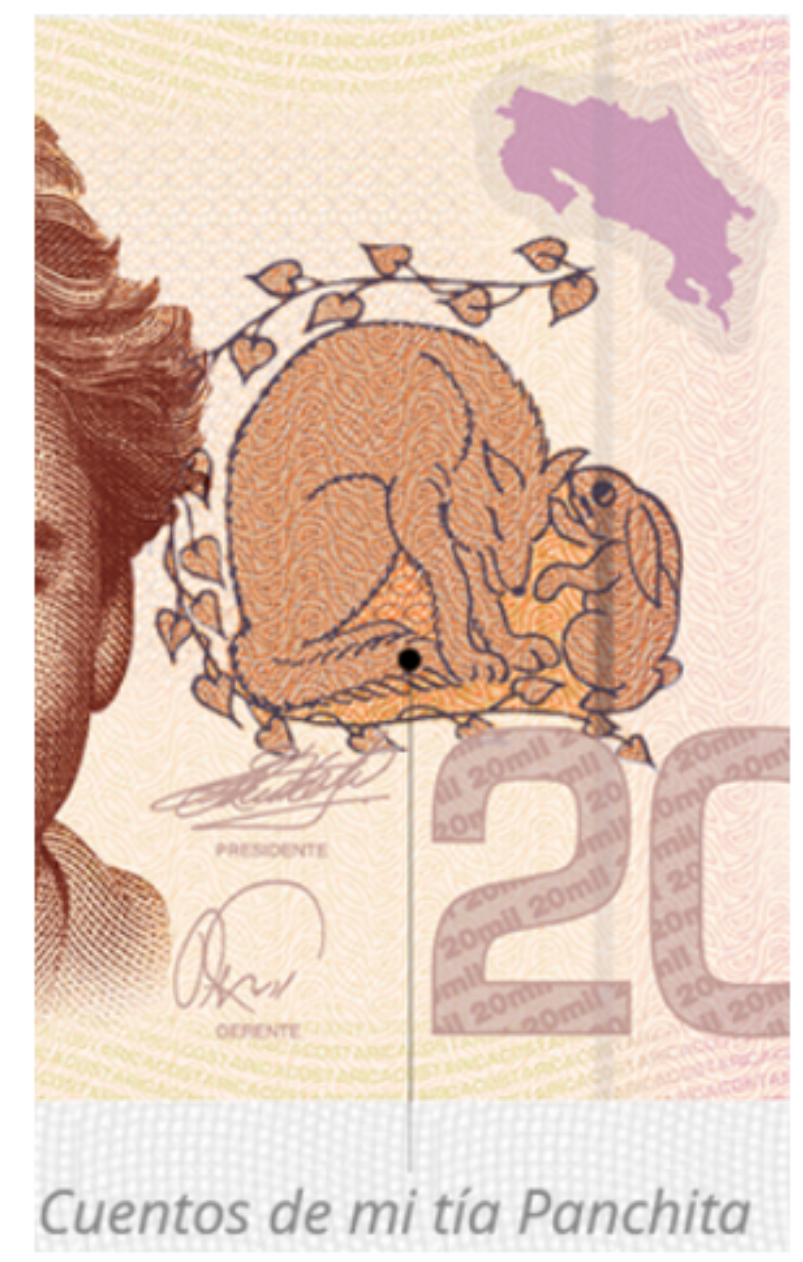

FIGURA 2

Los cuentos de mi tía Panchita, motivo del anverso del billete de 20.000 colones Fuente: Brand Voice de Grupo Nación (2017).

\section{Centenario de Los cuentos de mi tía Panchita}

La primera edición de Los cuentos de mi tía Panchita fue publicada en 1920, consta de 159 páginas y compiló 15 cuentos sin ilustraciones, fue editada por Joaquín García Monge, quien fue pedagogo, director de la Biblioteca Nacional, de la Escuela Normal de Costa Rica y de la revista Repertorio Americano (1919-1958). 
A partir de 1956, sus ediciones se conforman por 23 cuentos, divididos en dos partes: Cuentos de mi tía Panchita, con 13 relatos y Cuentos de tío Conejo, con 10 relatos.

Este editorial celebra los 100 años de Los cuentos de mi tía Panchita (1920-2020), un libro de gran relevancia para la literatura infantil costarricense, a través del cual, han llegado los aportes de Carmen Lyra, gran pedagoga y escritora, a toda la sociedad costarricense.

\section{REFERENCIAS BIBLIOGRÁFICAS}

Asamblea Legislativa. (6 de agosto de 1976). Declara Benemérita de Cultura Nacional a María Isabel Carvajal Quesada (Carmen Lyra). La Gaceta: Diario oficial, Decreto $\mathrm{N}^{\circ} 1679$

Asamblea Legislativa. (16 de mayo de 2016). Declara como Benemérita de la Patria a María Isabel Carvajal Quesada, conocida como Carmen Lyra, educadora, escritora y política. La Gaceta: Diario oficial, Decreto N6612-15-16

Banco Central de Costa Rica. (s.f.). Nuestro billete de \$20.000. Recuperado de https://bit.ly/2N9GSPe

Brand Voice de Grupo Nación. (2017). Billete de \$20.000. Recuperado de https://bit.ly/2Yb9Kg7

Lemistre-Pujol, A. (2015). Carmen Lyra: el cuento de su vida. San José: SIEDIN.

\section{BY-NC-ND}

